\title{
Effect of Maternal Fever on Fetal Behavior Assessed by KANET Test
}

Amira Talic, Asim Kurjak, Ulrich Honemeyer

\begin{abstract}
Objective of the study was to assess the possible effect of maternal fever without clinical chorioamnionitis on fetal behavior. In a period of 18 months, in a prospective longitudinal cohort study, Kurjak antenatal neurological test (KANET) was applied to assess fetal behavior in both normal pregnancies and pregnancies complicated by maternal fever. According to the primary localization of the infection, maternal fever group was divided into four groups: Respiratory tract infection, urinary tract infection, malaria and gastrointestinal tract infection. According to KANET test, fetuses with scores $\geq 14$ were considered normal, 6 to 13 borderline and abnormal, if KANET scores were $\leq 5$. Differences between groups were examined by Mann-Whitney U-test, differences between subgroups by Steel test. KANET scores differed statistically significant between two main groups. The largest proportion of abnormal KANET scores was found in pregnancies complicated by malaria, while the largest proportion of borderline scores showed fetuses from pregnancies complicated by urinary tract infection. There was no statistical significant difference in KANET scores between the control group and fetuses from pregnancies complicated by respiratory tract infection. KANET test has been shown to be a reliable means to distinguish normal and abnormal fetal behavior. Postnatal follow-up should confirm the data from prenatal assessment of fetal behavior.
\end{abstract}

Keywords: Fetal behavior, KANET scores, Maternal fever.

How to cite this article: Talic A, Kurjak A, Honemeyer U. Effect of Maternal Fever on Fetal Behavior Assessed by KANET Test. Donald School J Ultrasound Obstet Gynecol 2012;6(2):160-165.

Source of support: Nil

Conflict of interest: None declared

\section{INTRODUCTION}

A myriad of evidences implicate strong relationship between maternal infection during pregnancy and adverse neurological outcome, particularly cerebral palsy (CP). There is a strong evidence that maternal infections cause preterm birth and, in premature infants, brain lesions predictive of CP. Fifty percent of cerebral palsy occur in preterm infants. ${ }^{1}$ Approximately $25 \%$ of preterm births are caused by maternal infection/inflammation. ${ }^{2,3}$ Thus, any condition that increases risk of preterm birth is a potential risk factor for CP. There is accumulating evidence that maternal infection not only contributes to preterm labor, but also increases the risk for adverse neurological outcome in infants born at term. ${ }^{4}$ Grether et al reported CP in 37\% children born at term exposed to maternal infection $v$ s $3 \%$ control children. ${ }^{5}$ Neufeld et al reported two-fold increase in risk of CP in term children born after exposure to maternal infection. ${ }^{6} \mathrm{Wu}$ et al found that clinical chorioamnionitis four-fold increases risk of CP. ${ }^{7}$ These facts indicate a maternal infection as an independent risk factor for the development of CP in preterm and near term infants. ${ }^{8}$ Different underlying pathophysiological mechanisms may be involved in the process by which maternal infection causes CP: By immaturity after preterm birth, by causing overwhelming sepsis in the fetus or newborn, or by causing placental insufficiency and birth asphyxia. Recently, it also was proposed that activation of proinflammatory cytokines and the fetal systemic inflammatory response syndrome may cause fetal white matter injury directly. ${ }^{9-11}$

However, this study was not designed to determine the underlying mechanisms, but to assess a possible role of the maternal fever during the late second- and third-trimester in the development of abnormal fetal behavior.

Prenatal motility or fetal behavior reflects the function of the developing central nervous system. ${ }^{12-14}$ Therefore, the assessment of fetal behavior could allow distinction between normal and abnormal fetal behavior patterns which might make possible the early identification of fetal brain dysfunction. Development of the four-dimensional ultrasound techniques (4D US) has enabled an objective demonstration of fetal movements; even the movement of the face has become possible. ${ }^{15,16}$ Based on these facts, Kurjak et al standardized normal ranges of fetal movements appropriate for gestational age and created new scoring system for the assessment of the fetal behavior, Kurjak's antenatal neurodevelopmental test (KANET). The test is detailed described elsewhere. ${ }^{17}$ Recently, the test has been critically reviewed and modified (Figs 1 to 4 ). ${ }^{18}$

To estimate the impact of the maternal infection, as an independent factor in fetal behavior, we used KANET test with two goals: To assess fetal behavior in fetuses exposed to maternal fever originating nongenital infection without other symptoms of clinical chorioamnionitis, and to compare their KANET scores with those obtained from low-risk pregnancies.

\section{METHODS}

\section{Patients}

During the period of 18 months, from March 2009 until September 2010, in the prospective longitudinal cohort 


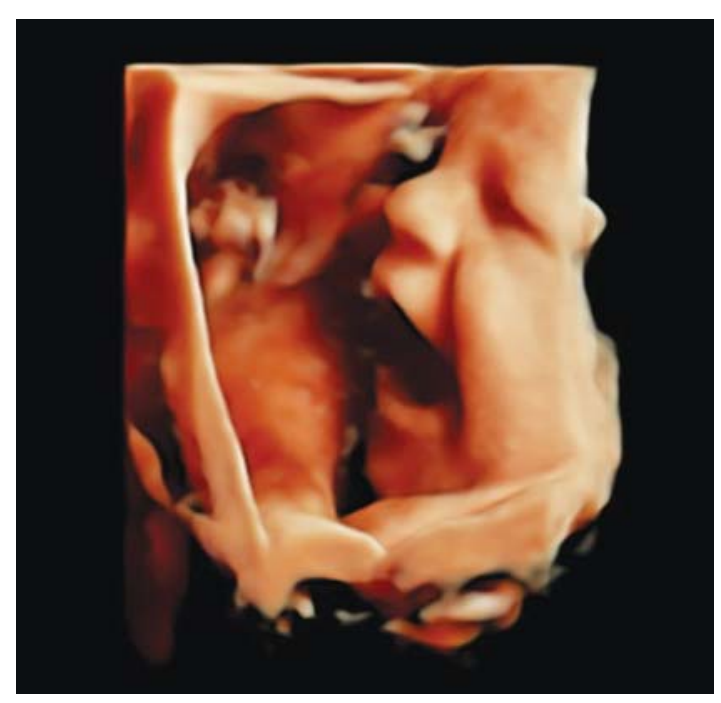

Fig. 1: Fetal yawning at 38 weeks

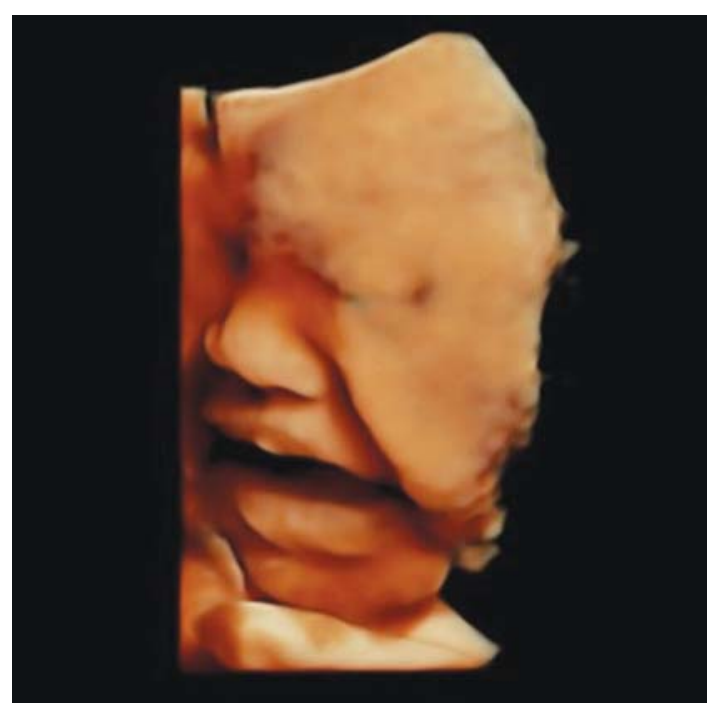

Fig. 2: Grimacing at 37 weeks

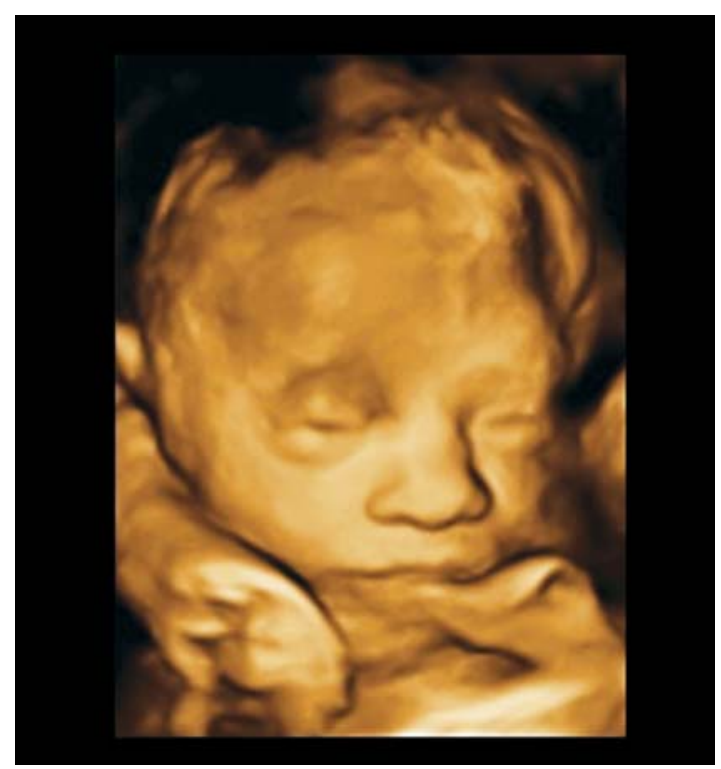

Fig. 3: Blinking at 26 weeks

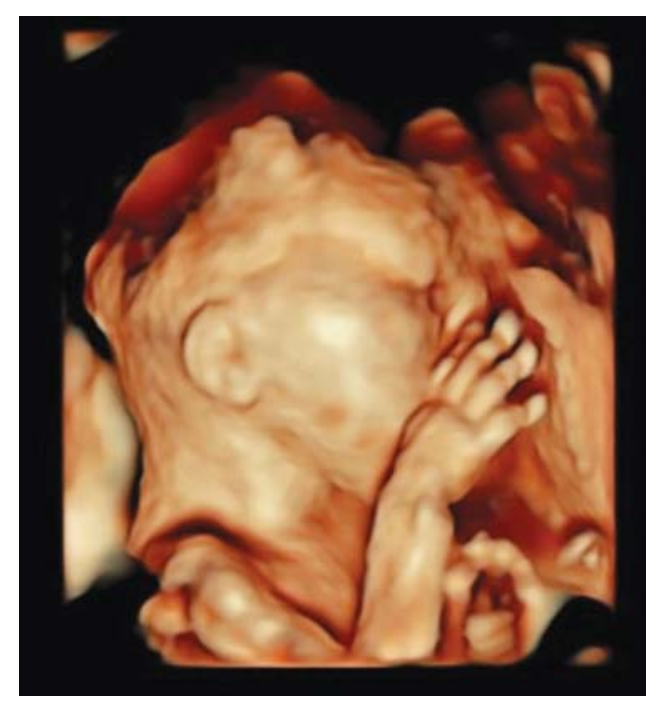

Fig. 4: Independent finger movement at 20 weeks

\begin{tabular}{|c|c|c|}
\hline Maternal characteristics & $\begin{array}{l}\text { Low-risk } \\
\text { group } \\
(N=100)\end{array}$ & $\begin{array}{l}\text { Maternal } \\
\text { fever } \\
(N=100)\end{array}$ \\
\hline Maternal age (SD) in years & $27.2(3.7)$ & $28.1(3.9)$ \\
\hline Percentage of nulliparous $(\mathrm{N})$ & $28(28 \%)$ & $25(25 \%)$ \\
\hline Mean maternal weight in $\mathrm{kg}(\mathrm{SD})$ & $67.2(6.8)$ & $64.6(5.9)$ \\
\hline
\end{tabular}

$\mathrm{N}$ : Number of examinees, SD: Standard deviation

study, KANET test was applied in 200 singleton pregnancies between 28th and 38th week of gestation. Gestational age was estimated by the first day of the last menstrual period and confirmed by the first- or early second-trimester ultrasound assessment. All participants have signed informed consent prior the inclusion in the study. Pregnant women were assigned in high- and low-risk group. Maternal characteristics are given in Table 1.

An inclusion criterion for the high-risk group was the presence of the maternal temperature above $38^{\circ} \mathrm{C}$ measured axillary, and absence of other known risk factors for adverse neurological outcome.

High-risk group consisted of 100 women, subdivided regarding to the underlying etiology of the fever into following subgroups: Urinary infection, respiratory infection, malaria and gastrointestinal tract infection. Respiratory infections included tuberculosis; influenza; influenza with pneumonia; bronchopneumonia; pneumonia, atypical; viral respiratory infections; acute bronchitis; and upper respiratory infections. Urinary tract infection (UTI) included acute cystitis and acute pyelonephritis, while women with known underlying renal pathology, chronic renal disease, renal transplant, diabetes, taking immunosuppression therapy or asymptomatic bacteriuria were excluded. Other exclusion criteria for the high-risk group are given in the Table 2 . 


\begin{tabular}{ll}
\hline \multicolumn{2}{c}{ Table 2: Exclusion criteria for the high-risk group } \\
\hline Maternal conditions & $\begin{array}{l}\text { Hypertension, diabetes type I or II, } \\
\text { thrombocytopenia }\end{array}$ \\
Pregnancy-related & $\begin{array}{l}\text { Gestational diabetes, Rh } \\
\text { immunization, placental bleeding } \\
\text { disorders }\end{array}$ \\
Fetal conditions & $\begin{array}{l}\text { Morphological abnormalities, } \\
\text { intrauterine growth restriction }\end{array}$ \\
Obstetrical history & $\begin{array}{l}\text { Previous offspring with an adverse } \\
\text { neurological outcome, previous } \\
\end{array}$ \\
& preterm birth, repeated miscarriages \\
\hline
\end{tabular}

Low risk, control group included 100 pregnant women with an uneventful present and past pregnancy course and expected clinical and ultrasound finding.

\section{Assessment of the Fetus}

All patients were evaluated by an experienced operator, using a transabdominal approach. The ultrasound equipment consisted of a MEDISON X8 machines with a $5 \mathrm{MHz}$ transabdominal transducer. After a systematic 2D examination of the fetus with detailed anatomical evaluation and measurement of the fetal growth, placenta, and amniotic fluid volume, the mothers were offered an assessment of fetal behavior by KANET scoring system, using 4D US. The assessments were performed between 10 am and $02 \mathrm{pm}$, while fetuses were awake. Fetuses from the highrisk group underwent to the second examination 2 weeks after resigning of signs of the maternal fever.

Mothers abstained from food, coffee and tea for 2 hours before the examination. The maximum duration of the examination was 30 minutes. The majority of fetuses exhibited normal activity already within the first 10 to 15 minutes, where upon KANET testing process was terminated. According to the scoring result, fetal behavior was classified into three groups: Normal with total KANET score of 14 to 20, borderline with total score of 6 to 13, and abnormal with total score of $\leq 5$ (test scores were given according to KANET scoring prior to modification by consensus meeting in Osaka). ${ }^{17,18}$

\section{Statistical Analysis}

Statistical analysis was performed to answer the following questions:

- The distribution of fetuses from low risk and pregnancies complicated by maternal fever assigned to different KANET groups.

- The comparison of KANET scores between the highrisk and control group.

- The comparison of KANET scores fetuses in different subgroups of fetuses within the group complicated by maternal fever with those from low-risk group.

Numerical data were displayed as means and standard deviations or medians, while frequencies were expressed as percentages. Mann-Whitney U-test was used by application PAST version 2.00 (http://palaeo-electronica.org/2001_1/ past/issue1_01.htm). For the analysis of KANET scores of subgroups within the pregnancies complicated by maternal fever we used Steel test by application and Kyplot version 4 (http:// www.kyenslab.com/en/). p-values less than or equal to 0.05 was considered as statistically significant.

\section{RESULTS}

KANET scores from low risk and pregnancies complicated by maternal fever are presented in the Table 3.

After statistical analysis using Mann-Whitney U-test, statistical highly significant difference between two groups of fetuses was found.

After statistical analysis using Steel test, statistical significant differences in KANET scores between following subgroups of fetuses and low-risk group were found: Urinary tract infection ( $p=0.0025)$, malaria ( $p=0.01989)$, gastrointestinal tract infection ( $\mathrm{p}=0.0409)$. There was no statistical significant deference in KANET scores between fetuses from low risk and pregnancies complicated by maternal fever. The largest proportion (19.4\%) of borderline scores was found in fetuses exposed to maternal fever caused by urinary tract infection. The largest proportion of abnormal KANET scores (6.6\%) showed fetuses of mothers having malaria.

\section{DISCUSSION}

The major finding of this study was that maternal fever was associated with significant changes in fetal behavior when estimated by applying KANET test. The effect of maternal fever on fetal behavior appears to be greater when it is caused by urinary tract infection ( $p=0.0025)$, than in fever caused by the gastrointestinal tract infection ( $p=0.0409$ ), or malaria ( $p=0.0189$ ). Maternal fever caused by respiratory tract infection in the present study did not affect fetal behavior (statistically significant) (Tabels 4 and 5).

An increasing number of evidence supports the concept that fetal inflammation caused by maternal infection contributes to neonatal brain injury. ${ }^{7}$ Majority of studies in

Table 3: The distribution of normal, borderline and abnormal KANET scores in low risk and pregnancies complicated by maternal fever

\begin{tabular}{lcccc}
\hline Group & $N$ & \multicolumn{3}{c}{ KANET scores } \\
\cline { 3 - 5 } & & $\begin{array}{c}\text { Normal } \\
(\%)\end{array}$ & $\begin{array}{c}\text { Borderline } \\
(\%)\end{array}$ & $\begin{array}{c}\text { Abnormal } \\
(\%)\end{array}$ \\
\hline Low risk & 100 & $94(94 \%)$ & $4(4 \%)$ & $2(2 \%)$ \\
Maternal fever & 100 & $82(82 \%)$ & $14(14 \%)$ & $4(4 \%)$ \\
\hline
\end{tabular}

$\mathrm{N}$ : Number of examinees 
Effect of Maternal Fever on Fetal Behavior Assessed by KANET Test

\begin{tabular}{llllll}
\hline \multicolumn{7}{c}{ Table 4: Comparison of KANET scores in low risk and pregnancies complicated by maternal fever } \\
\hline Group & $N$ & Mean (range) & SD & Median (Q1-Q3) & $p$-value \\
\hline Low risk & 100 & $16.75(2-20)$ & 2.71 & $17(16.25-18)$ & 0.0001 \\
Maternal fever & 100 & $14.01(3-18)$ & 5.19 & $15(13.75-16.75)$ & \\
\hline
\end{tabular}

(Mann-Whitney U-test); N: Number of examinees; Q1: The first quartile: 25th percentile; Q3: The third quartile: 75th percentile

Table 5: The distribution of KANET scores within subgroups of fetuses from pregnancies complicated by maternal fever

\begin{tabular}{cccccc}
\hline \multirow{2}{*}{\begin{tabular}{c} 
Etiology of the fever \\
\cline { 2 - 5 }
\end{tabular}} & $N$ & $\begin{array}{c}\text { Normal } N \\
(\%)\end{array}$ & $\begin{array}{c}\text { Borderline } N \\
(\%)\end{array}$ & $\begin{array}{c}\text { Abnormal N } \\
(\%)\end{array}$ \\
\hline RTI & 37 & $31(83.8)$ & $5(13.5)$ & $1(2.7)$ & 0.0782 \\
UTI & 26 & $21(80.7)$ & $4(19.04)$ & $1(3.8)$ & 0.0025 \\
Malaria & 15 & $12(80)$ & $2(13.3)$ & $1(6.6)$ & 0.0189 \\
GITI & 22 & $18(81.8)$ & $3(13.6)$ & $1(4.5)$ & 0.0409 \\
\hline Total & 100 & $82(82)$ & $14(14)$ & $4(4)$ & \\
\hline
\end{tabular}

N: Number of examinees; RTI: Respiratory tract infection; UTI: Urinary tract infection; GITI: Gastrointestinal tract infection

this field considers an effect of clinical chorioamnionitis on the risk for the development of cerebral palsy. Wu et al reported a significant association between clinical and histological chorioamnionitis and both cerebral palsy and cystic periventricular leukomalacia in preterm infants. Among term infants, positive correlation was found between clinical chorioamnionitis and cerebral palsy. ${ }^{7}$ Stanley et al conclude that congenital infections account for 5 to $10 \%$ of the cases of cerebral palsy. ${ }^{19}$ It has been accepted that maternal infections cause a significant number of cases of $\mathrm{CP}$ based exclusively upon their influence on the rate of prematurity. ${ }^{20}$ Nongenital tract infections also increase the risk of premature birth. Romero et al reported a strong correlation between urinary tract infection and preterm birth. ${ }^{21}$ Maternal pneumonia and appendicitis are risk factors for preterm birth. ${ }^{22}$ Periodontal disease is suspected to be most common maternal infection causing preterm birth. ${ }^{23}$

Grether et al report an association between CP and maternal fever during the labor, caused by clinical chorioamnionitis. ${ }^{5}$ Lawrence et al found a strong correlation between maternal fever during labor and adverse neurological outcome regardless of the underlying mechanism. They also suggest that a fever represents a largely independent pathway in the development of the neurological damage. $^{24}$

Respecting the fact that fetal behavior directly reflects developmental and maturational processes in fetal central nervous system, the assessment of fetal behavior in different periods of gestation promises early detection of abnormal brain development and various functional CNS abnormalities. ${ }^{12}$ Improvement in technology of 4D US has made possible the observation of plenty of various types of fetal movements. ${ }^{25,26}$ This opportunity has aroused a large interest of the academic community in intriguing area of the functional human brain development. As a result of the longitudinal analysis of normal fetal behavior in all threetrimesters of pregnancy, KANET test represents the reliable tool for the assessment of fetal behavior. Several studies have confirmed the potential of the test to differentiate between normal and abnormal fetal behavior both in structural normal and fetuses with congenital abnormalities. ${ }^{27-31}$

The present study relies on that background. The focus of this study was fetal behavior in condition of current maternal fever, but without other symptoms inherent to the clinical chorioamnionitis. Obtained results are consistent with the available data from the literature. McCallaghan et al found that preterm birth, intrauterine growth restriction, perinatal infection, and multiple pregnancies represent the largest risks for CP. In the study, that encompassed 587 individuals with CP and 1,154 non-cerebral palsy controls, upper respiratory tract during pregnancy were not associated with an increased risk of CP. ${ }^{32}$ Polivka et al reported 4 to 5 fold increased risk of having a child with $\mathrm{CP}$ in mothers who had a urinary tract infection during pregnancy. ${ }^{33}$ Mann et al reported the strong correlation between maternal genitourinary infection and CP in preterm infants. Infection was not associated with CP in infants of normal birth weight. ${ }^{34}$ Data from the present study suggests the occurrence of the abnormal fetal brain function during the pregnancy, independent of prematurity. However, the study assessed fetal behavior in pregnancies complicated by urinary tract infection regardless of the microbial agent. Obligatory criteria for the inclusion were the presence of the maternal fever and acuteness of infection. Hence, uneven selection of the including criteria may be a limitation for 
the interpretation of results. Further research is needed to assess the relationship between urinary tract infection during pregnancy and CP in offspring.

\section{CONCLUSION}

Maternal fever during pregnancy is considerable common problem. The strong link between chorioamnionitis and preterm birth and subsequent cerebral palsy is well documented. The purpose of this study was to assess possible correlation between maternal fever, without other symptoms of chorioamnionitis; and fetal behavior. We found statistical significant changes in fetal behavior among fetuses exposed to maternal fever. Further analysis showed that primary localization of the primary infection significantly affects the impact of maternal fever on fetal behavior. Considering the importance of neurological disorders in public health due to massive costs for the treatment, and their effect on the individual life quality, early detection and better understanding of their pathophysiology is an immense challenge for the modern obstetrics. Fetal behavior is a window to view the functional status of the fetal brain. Thus, identification of abnormal behavioral pattern offers a hope for the early diagnosis of neurological impairment. KANET test represents a reliable tool for the distinction of fetal behavioral patterns.

\section{REFERENCES}

1. McCormick MC. The contribution of low birth weight to infant mortality and childhood morbidity. N Engl J Med 1985;312: 82-90.

2. Goncalves LF, Chaiworapongsa T, Romero R. Intrauterine infection and prematurity. Ment Retard Dev Disabil Res Rev 2002;8:3-13.

3. Goldenberg RL, Culhane JF, Iams YD, Romero R. Epidemiology and causes of preterm birth. The Lancet 2008;371(9606): 75-84.

4. Romero R, Gotsch F, Pineles B, Kusanovic JP. Inflammation in pregnancy: Its roles in reproductive physiology, obstetrical complications, and fetal injury. Nutr Rev 2007;65:S194-202.

5. Grether JK, Nelson KB. Maternal infection and cerebral palsy in infants of normal birth weight. JAMA 1997;278(3):207-11.

6. Neufeld MD, Frigon C, Graham AS, et al. Maternal infection and risk of cerebral palsy in term and preterm infants. J Perinat 2005;25:108-13.

7. Wu YW, Colford JM, Jr. Chorioamnionitis as a risk factor for cerebral palsy: A meta-analysis. JAMA 2000:20;284:1417-24.

8. Wu YW, Escobar GJ, Grether JK, Croen LA, Greene JD, Newman TB. Chorioamnionitis and cerebral palsy in term and near-term infants. JAMA 2003;290(20):2677-84.

9. Romero R, Chaiworapongsa T. Preterm labor, intrauterine infection, and the fetal inflammatory response syndrome. Neo Reviews 2002;3(5):e73-84.

10 Yoon BH, Jun JK, Romero R, et al. Amniotic fluid inflammatory cytokines (interleukin-6, interleukin-1b, and tumor necrosis factor -a), neonatal brain white matter lesions, and cerebral palsy. Am J Obstet Gynecol 1997;177:19-26.

11. Gomez R, Romero R, Ghezzi F, et al. The fetal inflammatory response syndrome. Is J Obstet Gynecol 1998;197:194-202.

12. Prechtl HFR. Qualitative changes of spontaneous movements in fetus and preterm infant are a marker of neurological dysfunction. Early Hum Dev 1990;23:151-58.

13. Di Pietro JA, Bronstein MH, Costigan KA, et al. What does fetal movement predict about behavior during the first 2 years of life? Dev Psichobiol 2002;40:358-714.

14. Di Pietro JA, Hodgson DM, Costigan KA, Johnson TR, et al. Fetal state concordance predicts infant state regulation. Early Hum Dev 2002;68:1-13.

15. Kurjak A, Azumendi G, Andonotopo WA. Three- and fourdimensional ultrasonography for the structural and functional evaluation of the fetal face. Am J Obstet Gynecol 2007;196: 16-28.

16. Kurjak A, Predojevic M, Stanojevic M, Talic A, Honemeyer U, Salihagic-Kadic A. The use of 4D imaging in the behavioral assessment of high-risk fetuses. Imaging Med 2011;3(5): 557-69.

17. Kurjak A, Miskovic B, Stanojevic M, Amiel-Tisson C, Ahmed B, Azumendi G, et al. New scoring system for fetal neurobehavior assessed by three- and four- dimensional sonography. J Perinat Med 2008;36:73-81.

18. Stanojevic M, Talic A, Miskovic B, Vasilj O, Shaddad AN, Ahmed B, et al. An attempt to standardize Kurjak's antenatal neurodevelopmental test: Osaka Consensus Statement. DSJUOG 2011;5(4):317-29.

19. Stanley F, Blair E, Alberman E. Causal pathways initiated preconceptionally or in early pregnancy. In: cerebral palsies: Epidemiology and causal pathways. London: MacKeith Press 2000;48-59.

20. Hermansen MC, Hermansen MG. Perinatal infections and cerebral palsy. Clin Perinatol 2006;33:315-33.

21. Romero R, Ovarzun E, Mazor M, et al. Meta-analysis of the relationship between asymptomatic bacteriuria and preterm delivery low birth weight. Obstet Gynecol 1989;73:576-82.

22. Goldenberg RL, Culhane JF, Johnson DC. Maternal infection and adverse fetal and neonatal outcomes. Clin Perinatol 2005;32:523-59.

23. Mitchell-Lewis D, Engebretson SP, Chen J, et al. Periodontal infections and preterm birth: Early findings from a cohort of young minority women in New York. Eur J Oral Sci 2001;109(1):34-39.

24. Lawrence WM, Greenwood CEL, Black RS, Yeh PS-Y, Shejl $\mathrm{O}$, Doyle $\mathrm{P}$. The relationship between intrapartum maternal fever and neonatal acidosis as risk factors for neonatal encephalopathy. Am J Obs \& Gyne 2008;198(1):49.e1-e6.

25. Kurjak A, Pooh R, Tikvica A, Stanojevic M, Miscovic B, Ahmed B, Azumendi G. Fetal Neurology. In: Pooh RK, Kurjak A (Eds). Assessment of Neurobehavior by 3D/4D ultrasound (1st ed) 2009; chapter 7:222-85.

26. Kurjak A, Predojevic M, Stanojevic M, Talic A, Honemeyer U, Salihagic Kadic A. The use of $4 \mathrm{D}$ imaging in behavioral assessment of high-risk fetuses. Imaging in Medicine 2011;3(5):557-69.

27. Kurjak A, Abo-Yaqoub S, Stanojevic M, Yigiter AB, Vasilj O, Lebit $\mathrm{D}$, et al. The potential of 4D sonography in the assessment of fetal neurobehavior-multicentric study in high-risk pregnancies. J Perinat Med 2010;38:77-82. 
28. Talic A, Kurjak A, Ahmed B, Stanojevic M, Predojevic M, Salihagic Kadic A, Di Renzo GC. The potential of 4D sonography in the assessment of fetal behavior in high-risk pregnancies. J Matern Fetal Neonatal Med 2011;24(7):948-54.

29. Predojević M, Stanojević M, Vasilj O, Kadić AS. Prenatal and postnatal neurological evaluation of a fetus and newborn from pregnancy complicated with IUGR and fetal hypoxemia. J Matern Fetal Neonatal Med May 2011;24(5):764-67.

30. Talic A, Kurjak A, Stanojevic M, Honemeyer U, Badreldeen A, Direnzo GC. The assessment of fetal brain function in fetuses with ventrikulomegaly: The role of the KANET test. J Matern Fetal Neonatal Med 28 Nov 2011.

31. Miskovic B, Vasilj O, Stanojevic M, Ivankovic D, Kerner M, Tikvica A. The comparison of fetal behavior in high-risk and normal pregnancies assessed by four-dimensional ultrasound. J Matern Fetal Neonatal Med 2010; 23(12):1461-67.

32. O’Callaghan ME, MacLennan AH, Gibson CS, McMichael GL, Haan EA, Broadbent JL, et al. Australian Collaborative Cerebral Palsy Research Group. Epidemiologic associations with cerebral palsy. Obstet Gynecol.2011; 11(83): 576-82.

33. Polivka BJ, Nickel JT, Wilkins JR 3rd. Urinary tract infection during pregnancy: A risk factor for cerebral palsy. J Obstet Gynecol Neonatal Nurs 1997;26(4):405-13.
34. Mann JR, McDermott S, Bao H, Bersabe A. Maternal genitourinary infection and risk of cerebral palsy. Dev Med Child Neurol 2009;51(4):282-88.

\section{ABOUT THE AUTHORS}

\section{Amira Talic (Corresponding Author)}

Department of Obstetrics and Gynecology, Al Ain Hospital, Al Ain UAE, e-mail: talicamira@hotmail.com

\section{Asim Kurjak}

Professor, Department of Obstetrics and Gynecology, Medical School University of Zagreb, Clinical Hospital 'Sveti Duh', Zagreb

Dean, Faculty of Health Sciences, Dubrovnik International University Dubrovnik, Croatia

\section{Ulrich Honemeyer}

Specialist, Department of Mother and Child, Welcare Hospital EHL Dubai, UAE 